\title{
RELACIÓN ENTRE VALORES Y PRINCIPIOS GENERALES DE DERECHO EN LA INTERPRETACIÓN CONSTITUCIONAL DE LOS DERECHOS FUNDAMENTALES EN CHILE
}

\author{
RELATIONSHIP BETWEEN MORAL AND GENERAL LAW \\ PRINCIPLES IN THE CONSTITUTIONAL INTERPRETATION \\ OF BASIC RIGHTS IN CHILE
}

\author{
ENRIQUE ALCALDE RODRÍGUEZ
}

\begin{abstract}
RESUMEN: En estas notas se analiza el rol que desempeñan los valores y principios jurídicos desde la perspectiva de la interpretación constitucional de los derechos fundamentales, con especial referencia al sistema jurídico chileno. En dicho contexto, se procura identificar los riesgos y peligros que trae aparejados la introducción indiscriminada de tales elementos hermenéuticos, en tanto puede abrir un cauce con márgenes excesivamente amplios para la subjetividad del intérprete, afectando con ello la seguridad jurídica.
\end{abstract}

Palabras clave: Principios generales, valores y principios jurídicos, interpretación constitucional, derechos fundamentales

ABSTRACT: This article discusses the role of moral and general law principles in the interpretation of basic constitutional rights, with specific reference to the Chilean legal system. In this context, the article seeks to identify the risks and hazards that may arise from the abuse of the incorporation of hermeneutic elements, as a result of the excessive influence of the interpreter's subjective opinions. Such subjectivity, in turn, damages the consistency of relevant legal standards.

Key words: General law principles, juridical values, constitutional interpretation, Basic Rights.

\section{A. INTRODUCCIÓN}

Las notas que siguen tienen por finalidad exponer acerca del rol que desempeñan, en el sistema jurídico chileno, los valores y principios en tanto elementos colacionados con la interpretación constitucional de los derechos fundamentales. En lo más específico, se pretende analizar en qué medida unos y otros sirven de sustento para la argumentación jurídica que elaboran jueces y juristas en este particular ámbito de materias, identificando, al mismo tiempo, los peligros que puede entrañar el recurso a este expediente hermenéutico. Para los señalados efectos, se examinarán las opiniones vertidas por

\footnotetext{
* Licenciado en Ciencias Jurídicas de la Pontificia Universidad Católica de Chile, Profesor de Derecho Civil, Pontificia Universidad Católica de Chile. Correo electrónico: ealcalde@philippi.cl
} 
un sector relativamente amplio de la doctrina nacional ${ }^{1}$, así como las resoluciones de que dan cuenta determinados fallos de nuestro Tribunal Constitucional, las cuales, a riesgo de simplificar el tema, pueden ser calificadas como aproximaciones axiológicas al asunto propuesto.

\section{B. VALORES Y PRINCIPIOS JURÍDICOS COMO ELEMENTOS DE LA INTERPRETACIÓN CONSTITUCIONAL}

A modo de introducción, y desde una perspectiva general, suele afirmarse que en los modernos modelos de Constituciones pueden distinguirse tres elementos fundamentales, a saber: (a) Un núcleo central de ideas que configuran verdaderos principios y valores del respectivo régimen constitucional; (b) Una ordenación de las instituciones de gobierno en sentido estricto, y en la que se define la atribución de poder a los órganos que la misma establece; y (c) Un determinado orden económico y social en que se basa el orden mismo de la comunidad (familia, propiedad, economía, grupos intermedios, etc.) mediante los cuales tales instituciones desenvuelven su vida propia ${ }^{2}$. Para nuestro estudio interesa destacar, de manera especial, el primero de los grupos recién referidos, en cuanto algunos autores han pretendido alojar en él conceptos que, participando de la naturaleza de un "valor" o "principio", tienen por primera virtud la de orientarnos en relación con aquello que constituye la base y fundamento del orden institucional de una determinada comunidad. En este sentido, se ha dicho que tales principios se nos presentan como verdaderos valores normativos que inspiran el conjunto del ordenamiento jurídico, aun cuando no se encuentren exteriorizados conforme al modo de ser habitual de las normas. Ocurre, pues, que para una tal opinión "la realidad no se halla regulada exclusivamente por mandatos o preceptos externos sino por una serie de ideas de valor jurídico no formuladas exteriormente. El Estado, llamado a configurar la sociedad con arreglo a la Constitución, no puede obrar en todo caso por medio de normas compiladas, sino que su actividad solo cobra sentido a través de los Principios"3. De esta suerte, los principios generales del derecho que, al decir de Díez-Picazo, otrora planeaban por encima del ordenamiento como espíritus puros o casi angélicos, se encarnan y concretan en la Constitución y en ella obtienen el medio técnico y eficaz de su función informadora. Tanto es así, que ha llegado a

\footnotetext{
${ }^{1}$ Así, por ejemplo, y según se verá en el curso de esta exposición, SilvVA (1979) p. 118; (1984) p. 7 y CEA (1992) pp. 93, 94 y 97; ZAPATA (1994) p. 87; BARROS (1981) pp. 28, 29, 32 y 33; y Bustos (1986) p. 167.

2 Sánchez Agesta, citado por CASTEDO (1979) p. 434.

${ }^{3}$ Carretero (1979) p. 395. Complementando tal razonamiento, agrega que "es preciso por lo tanto clarificar en qué sentido se acepta el concepto de Ordenamiento Jurídico para superar una concepción formalista del Derecho. La realización de la Justicia, que es la finalidad del Derecho, se garantiza por el Ordenamiento; las leyes como Derecho Escrito no contienen todos los valores jurídicos, pues entonces se autojustificarían por sí mismas; el Derecho supera la ley; el enlace de los valores superiores de justicia y las reglas de conducta deducidas de la interpretación de las normas escritas, son los Principios generales del Ordenamiento" (pág. 393).
} 
sostenerse que, desde esta perspectiva, la Constitución hasta un cierto punto juega hoy como el subrogado positivamente tecnificado del derecho natural ${ }^{4}$.

Reflexiones como las precedentes no son ajenas, según veremos, a la opinión de un sector importante de la doctrina nacional. Con todo, y antes de profundizar en ello, resulta preciso al menos enunciar las diferencias fundamentales entre "valores", "principios" y "normas" . Se señala, primeramente, que la esencial diferencia entre "principio" y "norma" radica en la circunstancia de que mientras la segunda supone un marco definido que deslinda su aplicación, aquel, en cambio, al carecer de una descripción precisa del "hecho típico" destinado a regular, podría decirse que en sí mismo lleva envuelta su indeterminación. Por ello, este último constituye más bien una guía, pauta, criterio o, incluso, la causa y justificación de una norma o precepto en particular, pero en ningún caso una "instrucción” exhaustivamente acabada. En esta línea, Gordillo Cañas expresa que una diferencia separa a la norma legal de la principal: "la primera es una norma desarrollada en su contenido y precisa en su normatividad: acota y perfila los presupuestos de su aplicación, determina en detalle su mandato, establece posibles excepciones; el principio, por el contrario, expresa la inmediata y no desarrollada derivación normativa de los valores jurídicos: su presupuesto es sumamente general y su contenido normativo es tan evidente en su justificación como inconcreto en su aplicación. He aquí -concluye- por qué el principio, aun en aquellos casos en que ha sido legalmente formulado, sigue siendo principio, necesitado, por ello, de desarrollo legal y de determinación casuística en su aplicación judicial"6.

Atienza y Manero definen los principios en sentido estricto en términos del alcance de aplicación de una norma: "un principio define los casos a los que es aplicable de

4 GORDillo (1990) p. 64. Precisando algunas de las consecuencias que trae aparejada esta realidad, Gordillo manifiesta que, incorporados a la Constitución, tales principios adquieren el más alto rango normativo al servicio de su función informadora del ordenamiento, pero no por ello quedan convertidos en Ley formal, del mismo modo que la versión escrita de la costumbre no priva a esta de su peculiar carácter de norma consuetudinaria. (p. 84)

5 Para una conceptualización general y el rol que desempeñan los principios generales del derecho pueden verse las siguientes obras: AleXY (1998 y 2003); Altamira (1972); ArCE y Flórez VAldés (1990); Barros (1984); Carretero (1979); Courcelle-SEneuil (1986); Del VecChio (1948); DíeZ-PICAZO y GULLÓN (1989); DWORKIN (1984); ESSER (1961); FinNis (2000); FrEIXES Y REMOTTI (1992).

6 Gordillo Cañas (1990) p. 84. Para Betti, el término "principio" designa lo que se contrapone a "acabamiento", lo opuesto a norma completa y formulada. Principio es el pensamiento, la idea germinal, el criterio valorativo que la norma pone en ejecución; aquello que guarda relación con el problema práctico resuelto por la norma, inspirando su ratio, en sentido teleológico, en cuanto suministra el criterio de solución. Para el jurista italiano, "los principios son criterios valorativos supremos, que forman una excedencia de contenido deontológico o axiológico en relación con las normas singulares”. Citado por QUINTANA BRAVO (1994) pp. 106-108. Entre nosotros, similar predicamento patrocina Oelckers al afirmar que mientras la norma jurídica se caracteriza por ser prescriptiva, los principios, en cambio, tienen un carácter directivo y se refieren a géneros amplios de actuación, sin que observen la especificidad de aquella. "Así los principios actúan ante la norma jurídica como fundamento, razón, clave o argumento de interpretación, ya que responden a un modo más amplio y general de actuación. También responden a un fundamento para el cambio de criterio jurisprudencial o legal; también como fundamento de excepción de la ley o de nuevas leyes y por último como criterio de actuación a casos particulares, constituyéndose aquí como límites a la arbitrariedad...”. OelCKERS (1992) p. 371. Aun cuando este autor alude al ámbito de la norma jurídica administrativa, pensamos que su alcance es general y puede aplicarse en el sentido propuesto. 
forma abierta, mientras que las reglas lo hacen de forma cerrada". En cuanto a su utilidad, indican que "los principios son [...] más que las reglas [...] en dos sentidos. Por un lado, porque al estar enunciados -o poder enunciarse- en términos más generales [...], tienen un mayor alcance justificatorio. Por otro lado, [...][tienen] una mayor fuerza expansiva. Sin intentar explicar el término "fuerza expansiva", se puede indicar que la principal fuente de la fuerza justificatoria de los principios consiste en su vínculo uno-auno con los correspondientes valores. Cada principio corresponde a un valor determinado... de modo que "un principio en sentido escrito "expresa los valores superiores de un ordenamiento jurídico (que son el reflejo de una determinada forma de vida) ... Un valor puede ser definido como un criterio de valoración... Cada principio exige que el valor al que él mismo corresponde sea respetado tanto como sea posible ${ }^{7}$.

Dworkin, a su turno, plantea un distingo entre directrices, principios y normas. Las primeras las concibe como el tipo de "estándar" que propone un objetivo que ha de ser alcanzado, "generalmente, una mejora en algún rasgo económico, político o social de la comunidad". Denomina, en cambio, principio, a un "estándar" que debe ser observado, "no porque favorezca o asegure una situación económica, política o social, sino porque es una exigencia de la justicia, la equidad o alguna otra dimensión de la moralidad”. Finalmente, comentando la diferencia entre principios jurídicos y normas jurídicas, plantea que aquella es una distinción lógica: "Ambos conjuntos de estándares apuntan a decisiones particulares referentes a la obligación jurídica en determinadas circunstancias, pero difieren en el carácter de la orientación que dan. Las normas son aplicables a la manera de disyuntivas. Si los hechos que estipula una norma están dados, entonces o bien la norma es válida, en cuyo caso la respuesta que da debe ser aceptada, o bien no lo es, y entonces no aporta nada a la decisión. Pero no es así como operan los principios ... $\mathrm{Ni}$ siquiera los que más se asemejan a normas establecen consecuencias jurídicas que se sigan automáticamente cuando se satisfacen las condiciones previstas" 8 .

\footnotetext{
7 "Por otra parte, los principios en sentido estricto, según Atienza y Manero, pueden ser útiles, también, cuando el legislador tiene una razón para hacer una regla "fija" que resulte aplicable a un conjunto "no fijo" de casos, como ocurre por ejemplo en el supuesto de las cláusulas generales”. PECZENIK (1992) pp. 327 y 331. ${ }^{8}$ DWORKIN (1984) pp.74, 75 y 76. Para Alexy, "principios y valores son ... lo mismo, contemplado en un caso bajo un aspecto deontológico, y en otro caso bajo un aspecto axiológico. Esto muestra con claridad que el problema de las relaciones de prioridad entre principios se corresponde con el problema de una jerarquía de los valores". ALEXY (1998) p. 145. Entre nosotros, algunos han pretendido extrapolar las doctrinas de Alexy a fin de aplicarlas a la situación de los derechos fundamentales en Chile. Así, Ruiz-Tagle señala que "algunas de sus categorías pueden ser adaptadas con el objeto de comprender mejor el contenido de los derechos fundamentales en la Constitución chilena. Por ejemplo, si usamos la clasificación que distingue entre reglas y principios y la adaptamos a las disposiciones del artículo 19 de nuestra carta fundamental, podemos reconocer lo siguiente: Son principios en la clasificación de Alexy los No 1, incisos 1 y 2 ; No 2 inciso 1; No 3 incisos 1 y 2 segunda frase; No 4 inciso 1; No 5 parte del inciso 1; No 6 inciso 6; No 7 inciso 1; No 8 inciso 1; No 9 inciso 1 y 5; No 10, incisos 1, 2, 3, 4, 6 y 7; No 11 incisos 1, 2 y 4; No 12 incisos 1, 4, y 5; No 13 inciso 1; No 14 es totalmente un principio; No 15 incisos 1, 5, 6; No 16 inciso 1 y 2; No 17 es totalmente un principio constitucional; No 18 inciso 1 y 3; No 19 inciso 1 primera frase; No 20 inciso 1 y 2; No 21 inciso 1; No 22 inciso 1; No 23 inciso 1; No 24 inciso 1 y 2 en parte e inciso 9; No 25 incisos 1, 2 y 3 y finalmente el $\mathrm{No} 26$ es una regla en cuanto regula, limita o complementa derechos fundamentales pero es un principio en cuanto se funda en el principio de proporcionalidad de la afectación”. RUIZ-TAGLE (2001), pp. 197 y 198.
} 
Al decir de Franck Moderne, "el recurso a los principios generales del derecho se beneficia de una doble legitimidad: una legitimidad funcional, que se inscribe en la perspectiva de la racionalización del derecho, preludio de su racionalidad efectiva una vez terminado el proceso; y una legitimidad orgánica, que se vincula a la autoridad que elabora este tipo de normas, es decir, el juez". En lo que respecta a la primera, destaca que "en los procesos de racionalización de los derechos estatales contemporáneos, los principios generales desempeñan un rol eminente, inclusive determinante: ellos contribuyen a forjar la coherencia del orden jurídico normativo y sirven para llenar las lagunas del derecho" y, relativamente a su legitimidad orgánica, expresa que "en cuanto a la actividad "jurisprudencial" creadora de normas generales o de referencia, ella está en el origen, especialmente, de los "principios generales del derecho". El poder normativo del juez encuentra ahí, en resumen, su ilustración más tópica, aunque los partidarios de la corriente formalista clásica le niegan enérgicamente la existencia como fuente del derecho auténtico. La habilitación constitucional para juzgar (...) conlleva la habilitación para forjar normas jurisprudenciales por una especie de extensión natural del poder soberano atribuido al juez, el cual puede así insertarse en la jerarquía de las autoridades dotadas de un poder normativo" .

En un interesante trabajo, Freixes y Remotti, se pronuncian en torno al alcance de los valores y principios "positivados" en la Constitución, su diferenciación con las reglas, así como respecto de sus funciones que a aquellos corresponde en el ámbito constitucional, nociones todas que, aun generales, pueden ofrecer particular relevancia a la hora de analizar la interpretación de los derechos fundamentales de acuerdo a la opinión doctrinaria que analizamos.

Conforme a la exposición de los referidos autores, la positivación de los valores y principios, es decir, su inclusión en preceptos que, adicionalmente, gozan de eficacia directa, no permite, en primer lugar, eludir su aplicación ni, en segundo término, realizar cualquier interpretación valorativa. Agregan que, si bien en múltiples ocasiones, la

9 Moderne (2005) pp. 35, 36, 45 y 46. Con todo, luego de exponer la posición de quienes -como Genevois- estiman que existen principios generales con un valor constitucional, advierte que "la idea de que el juez constitucional esté capacitado, al igual que su homólogo del orden jurisdiccional-administrativo, para crear principios generales del derecho (con valor constitucional) y para imponerlos al legislador a título de control de constitucionalidad, no ha recibido una adhesión pacífica por parte de la doctrina”. En este sentido, agrega, "uno de los observadores más autorizados de la jurisprudencia constitucional, el Decano G. Vedel, no escondía su reticencia ante la eventual creación de principios generales del derecho constitucional, análogos mutatis mutandis a los principios generales del derecho administrativo (...) observaba que "la garantía más segura de la estabilidad, si no de la perennidad, de la jurisprudencia constitucional, se encuentra en el hecho que el Consejo Constitucional, ampliamente alertado contra el gobierno de los jueces, no se considere dueño de las fuentes del derecho constitucional. Casi no podemos citar motivación, de cada una de sus resoluciones, que no se refiera con precisión a un texto de valor constitucional". Y, continuando: "no existe en Derecho una no man s land [tierra de nadie] constitucional (...) Toda la Constitución, y nada más que la Constitución, tal parece ser el campo de las normas, aplicables por el juez constitucional francés". Por lo mismo, concluye Moderne afirmando "en lo que se refiere al derecho francés, que la jurisprudencia constitucional se niega a crear fuentes "complementarias" de la Constitución que vendrían a agregarse a la fuente principal, bajo la forma de PRINCIPIOS GENERALES DE DERECHO CONSTITUCIONAL. (pp. 128, 129 y 130.) 
doctrina e incluso la jurisprudencia constitucional han utilizado indistintamente los términos "principios" y "valores" identificándolos, en el fondo, con la estructura normativa de los "conceptos jurídicos indeterminados", los valores no son idénticos a los principios ni en su estructura ni en su función.

Los valores, en su opinión, enumeran cláusulas generales o finalidades, mientras que las reglas contienen disposiciones específicas y, tanto unos como otras están positivados, es decir, constan de forma explícita y concreta, pudiendo, por ende, apreciarse a través de una simple interpretación lingüística. Los principios, en cambio, se extraen de las reglas constitucionales, y, una vez determinados, tienen proyección normativa; consisten, pues, en fórmulas de derecho fuertemente consensuadas que albergan en su seno gérmenes de reglas jurídicas; lo que equivale a afirmar que los principios no siempre constan explícitamente en el texto constitucional, aunque pueden fácilmente deducirse del mismo a través de una interpretación estructural y sistemática. De igual modo, hacen ver que los valores, en términos de Stick, son "impredictibles", en el sentido que plantean diversidad de opciones jurídicas libres, mientras que los principios, según el mismo autor, son, en cambio, "indeterminados" y comportan la discrecionalidad del intérprete, que se concreta en criterios objetivos que el propio derecho proporciona, teniendo en cuenta que la indeterminación reside en el grado de relación del principio con las reglas que de él pueden derivar, no en relación al propio principio.

Concluyen, a modo de síntesis, que la positivación constitucional de los valores comporta, en cuanto a su estructura jurídica: (i) Su transformación en reglas prescriptivas y vinculantes; (ii) Su condición de metanormas orientadas a la producción de otras normas; (iii) La estabilidad de sus características estructurales; y (iv) Una relación de complementariedad, y no de jerarquía. Asimismo, y en relación con su específico rol constitucional, ambos autores siguen a Pérez Luño en cuanto se atribuye a los valores una función fundamentadora, desde el momento que son el núcleo básico e informador de todo el ordenamiento; una función orientadora, ya que dirigen el ordenamiento hacia metas o fines predeterminados, y una función crítica, dado que sirven como criterio o parámetro de valoración de hechos o conductas. En razón de lo dicho, destacan el hecho que los principios constitucionales, una vez determinados, adquieren proyección normativa y, al igual que los valores, son instituciones jurídicas vinculantes para los poderes públicos. Por último, y a propósito de las peculiaridades que reviste la interpretación de los valores y principios constitucionales, Freixes y Remotti postulan que esta debe seguir las reglas generales de la interpretación jurídica, no obstante lo cual debe considerarse, a partir de su especial estructura normativa y su función constitucional, una serie de singularidades que, para los efectos que aquí nos interesan, se pueden resumir como sigue: (i) Tanto valores como principios tienen, respectivamente, una estructura jurídica estable y permanente, mientras que, por otra parte, su función constitucional es flexible y dependiente de múltiples circunstancias que pueden generar una pluralidad de opciones; (ii) Cuando entre los valores subyacentes a las normas exista conflicto o, en su caso, lo exista entre los principios extraídos de las mismas, debe encontrarse una interpretación que no anule ninguno de los valores o, en su caso, principios; (iii) Ni entre principios por un lado ni entre valores 
superiores por otro, puede establecerse un orden jerárquico interno, ya que la Constitución no lo determina ${ }^{10}$.

Ahora bien, relativamente a la doctrina nacional, un sector relevante de la dogmática constitucional con frecuencia recurre a los conceptos de "valor" o "principio" como marco contextual para interpretar el contenido y alcance de los derechos fundamentales que, explícita o implícitamente, consulta nuestra Carta Política. En este sentido, Ruiz-Tagle distingue dos grandes concepciones acerca de la dogmática constitucional de los derechos fundamentales. Identifica, así, un primer grupo, al que denomina concepciones "intuitivas", dotadas de un carácter total o jerarquizado, conforme a las cuales el derecho constitucional se concibe como encerrado en sí mismo o como inspirado en consideraciones extraconstitucionales que no se hacen del todo explícitas; intuitivo, en cuanto no responde a un criterio de derecho positivo, sino que emana de una intuición, entendida como lo opuesto a lo públicamente razonado; y que poseen también la condición de responder a un criterio total porque suponen que todos los conflictos se deben solucionar de una misma manera, y que todos los órganos deben resolver estos conflictos del mismo modo, sin discriminar entre diversos tipos de procedimientos. En oposición a esta corriente, postula su preferencia por aquel otro grupo de concepciones -que llama de carácter razonado y parcial- que suponen un rechazo del método intuitivo y de la adopción de jerarquías injustificadas respecto de los derechos, exigiendo que la inclusión de elementos morales, religiosos, políticos o económicos en los cuales se fundamenta la argumentación jurídica se mencionen en forma expresa. Dicha concepción propone, además, soluciones parciales y diferenciadas para los distintos casos, con especial atención al tipo de procedimiento o sede en la cual se discute la cuestión constitucional, reemplazando la idea de jerarquía por las de balance, delimitación y ponderación de los derechos ${ }^{11}$.

Entre las concepciones enunciadas, y como se advirtió al inicio de estas líneas, nos centraremos preferentemente en la posición adoptada por quienes, en la terminología precitada, adhieren a las doctrinas "jerarquizadas" como perspectiva de aproximación a la interpretación de los derechos fundamentales, toda vez que son precisamente estas las que suelen recurrir al concepto de "principio" o "valor" para determinar el contenido o alcance de tales derechos ${ }^{12}$.

Por de pronto, interesa destacar que aquellos que participan de esta visión, coinciden, a su vez, en el método hermenéutico que ellos mismos postulan debe seguirse preferentemente en el ámbito de la interpretación constitucional y que puede denomi-

\footnotetext{
10 FreiXes y REMOTTI (1992), pp. 98-105.

11 RuIZ-TAGLE (2001) pp. 183-188.

12 Una evidente confirmación de este aserto lo constituye la opinión de Cumplido, quien, al preguntarse cuáles son los valores supremos de nuestra Constitución Política, responde que entre ellos destacan aquellos contemplados "en los capítulos I "Bases de la Institucionalidad” y III "De los Derechos y Deberes Constitucionales"; agregando que tales disposiciones "tienen un carácter plenamente normativo, obligatorio para todas las personas y vinculantes para los órganos del Estado”. CUMPLIDO (1995) p. 135. Las cursivas son nuestras.
} 
narse como "científico-espiritual" o "valorativo"13. Así, por ejemplo, Cea plantea que "las normas constitucionales contienen valores, por lo común enunciados como principios, llámelos así o no en el texto respectivo (...) algunos formulados con tan escasa densidad determinativa que los principios sustentadores de ellos se presentan en lenguaje de cláusulas abiertas o conceptos jurídicos indeterminados [v.gr. proscripción de la censura previa, exclusión de los tributos manifiestamente desproporcionados o injustos, de no discriminación estatal en el trato económico] (...) Abundan en la Constitución las normas con principios y, ya lo destaqué, las que contienen únicamente un principio de norma. Felizmente ocurre así, porque gracias a esa textura abierta y algo imprecisa se abren al intérprete múltiples opciones de significado, todas idénticamente lícitas. El estilo constitucional tiene que ser claro, transparente y natural, pero reunir también los atributos de concisión, amplitud y generalidad que son típicos de los principios. Por dicha característica deviene más factible que la Constitución perdure, merced a una hermenéutica evolutiva fundada en la elasticidad de los preceptos, los cuales cobran vida y vigor sociológico por los valores incorporados o que laten por su rasgo de implícitos en ellos (...) Sea que declare o descubra, que cree o construya, en todo proceso hermenéutico el intérprete es fiel a la Constitución si opera dentro de los márgenes trazados por los valores objetivos de aquella" ${ }^{14}$. Como para despejar toda sombra de duda acerca de su

\footnotetext{
${ }^{13}$ Según Zúñiga, dicho método se caracteriza: (i) por tener en cuenta "las bases de valoración (sistema de valores) subyacentes al texto constitucional" y (ii) porque "el sentido y realidad de la Constitución está dado como elemento del proceso de integración. El orden de valores obliga a una captación espiritual del contenido axiológico del orden constitucional. La interpretación del texto constitucional está destinada a desentrañar el sentido y realidad de una norma; articulando la norma a un integración espiritual real de la comunidad (valores, realidad existencial del Estado, etc.)". Asimismo, expresa que este método "se basa en la obra del juspublicista alemán R. Smend. La Constitución -dice Smend- no puede ser comprendida solo como un estatuto de la organización, que estructura el Estado y que faculta e impone ciertas actividades al mismo, sino, a la vez como una forma vital de los ciudadanos que participan en el Estado. Los valores comunes expresados y servidos por la Constitución operan, pues, como valores de integración colectiva de los ciudadanos y así deben sobre todo ser comprendidos y aplicados". ZUÑIGA (1992) p. 301. Algunos llaman a este método "teleológico", v. gr. RAMÓN (1979) p. 65.

14 CEA (1992) pp. 93, 94 y 97. En otro texto, el mismo autor añade, en lo que respecta al rol de los principios generales del derecho en materia de interpretación constitucional, que en el fondo de las normas jurídicas positivas "hay siempre latente un principio de derecho que, una vez descubierto, tiene en sí un impulso suficiente para cobrar rango igual a la ley misma. Ningún principio, sin embargo, actúa como creador de normas, sino que su valor constructivo lo alcanza en unión con el conjunto de ordenamiento reconocido, dentro del cual incumbe una función definida ...". Destacando la importancia de los principios, el mismo autor escribe: "Fuerza es agregar que (ellos) constituyen la base de complejos enteros de reglas e instituciones, hasta el punto de que si no son reconocidos, el ordenamiento completo quedaría falseado en un sentido y ninguna de sus disposiciones concretas podría dejar de ser afectada. Por ello los principios son fuente directa del derecho positivo. Justamente, el concepto material de la Constitución descansa en la admisión de tales principios inmanentes y obligatorios, estén o no formalmente aludidos o desarrollados por la normatividad positiva". En síntesis, su principal relevancia "reside en que sirven de claves interpretativas de las normas constitucionales, fijando consecuentemente el fundamento y límites de las reglas complementarias y de la aplicación de estas con subordinación a aquellos". Citado por ZAPATA (1994) p. 87. En la misma línea, y refiriéndose a los "valores" como elemento de toda interpretación, Silva Bascuñán, incluso con anterioridad a la promulgación de la Constitución vigente, ya proclamaba la necesidad de que la Constitución se fundara en el rechazo de las doctrinas del positivismo jurídico, "en cuanto este admite validez y vigencia a toda norma promulgada, cualquiera que sea su sustancia, aun a las que contradigan los requeri-
} 
posición, en otro trabajo el mismo autor expresa que "los principios son disposiciones jurídicas básicas y de gran generalidad que se irradian sobre todas las normas, imprimiéndoles sentido y sirviendo de criterio correcto para su exacta comprensión. Respetar íntegramente los principios constitucionales es, en consecuencia, la clave para conservar la Constitución ... Por eso, si el legislador transgrede un principio ofende no solo a las normas constitucionales que lo concretan, sino que además y, sobre todo, incurre en la más grave inconstitucionalidad, cual es la insurgencia contra todo el sistema jurídico, la subversión de sus valores fundamentales" 15 .

Barros, por su parte, refiriéndose al rol de los valores constitucionales, expresa que si bien de estos no se siguen directamente normas de conducta, ello no implica que carezcan de todo significado, siendo su función primordial la de servir como instrumentos de argumentación. En su concepto, "la Constitución representa un sistema de preferencias o valores que hay que articular honradamente, sobre la base de una argumentación que recurra a ideas y no al mero análisis formal del texto. Así, por ejemplo, un orden constitucional efectivo supone que las excepciones o limitaciones a los derechos o garantías (que están previstas en todas las constituciones) sean efectivamente entendidas como excepciones, que solo en casos graves sean admisibles. Una interpretación formalista de la Constitución podría llevar, por el contrario, a que, de hecho, las excepciones sean la regla general". De ahí que concluya que "La interpretación constitucional ... supone que se definan de modo muy intersubjetivo los valores o preferencias del sistema... La adecuada técnica de interpretación constitucional supone, en definitiva, convencerse de que la vieja máxima de Montesquieu -"el poder judicial es un poder neutro, casi nulo"- es especialmente falsa respecto de la Constitución"16.

mientos más evidentes de justicia. Un pluralismo aceptable en la sociedad democrática no puede reconocer, aunque cuenten con la adhesión mayoritaria y se sujeten a regularidad en su proceso formativo, la vigencia y validez de leyes o actos de autoridad que vulneren esos valores superiores y, al contrario, ha de establecer los resortes encaminados a que, si en el hecho se promulgan o decretan, queden privados de todo efecto en el campo jurídico. No basta la autolimitación del derecho por el mismo Estado propugnada por Jellinek y todavía seguida por Marcel Waline, ni admirar la lógica del normativismo de Kelsen sin completarla con el planteamiento de los problemas axiológicos que toda regla del derecho lleva envuelto". SILVA (1979) p. 118.

15 CEA (1984) p. 7. En la misma línea, aunque acotando en algo el margen de la labor interpretativa, se arguye que "los preceptos constitucionales tienen una imprecisión que les impide, de partida, operar como parámetro para extraer una solución jurídica automática. En los preceptos constitucionales no es posible descubrir referencias a conductas concretas o a consecuencias determinadas. Por el contrario, la mayoría de tales preceptos se integran por referencia a valores, principios, derechos, bienes e instituciones de formulación muy genérica y de significado, en ocasiones, no unívoco, puesto que, en muchas ocasiones, expresan un compromiso entre intereses diversos o, incluso, contradictorios... La interpretación constitucional no se entiende como la búsqueda de la regla implícita en el texto, sino como la concreción de los contenidos del texto mediante la elaboración de la regla que debe ser aplicada a cada supuesto de hecho a partir de los principios que el propio texto brinda”. CARRASCO (1997) p. 117.

16 BARros (1981) pp. 28, 29, 32 y 33. A propósito de lo dicho, y refiriéndose a la dialéctica que revela la exégesis de un texto constitucional, Bustos expresa que "así como no hay texto constitucional neutro, tampoco hay intérprete neutro. Se está o no se está en el espíritu de la Constitución; se participa o no con su ideología; y el problema nace, obviamente, cuando ello no ocurre. Porque la conclusión lógica de la situación aludida no puede ser más clara: quien no participa realmente de los valores consagrados en la Constitución no está habilitado para interpretarlo. Si, existencialmente, el exégeta sustenta otra ideología 
Desde la perspectiva que comentamos, y en lo relacionado más explícitamente con la interpretación de los derechos fundamentales, Ferrada destaca que para las posiciones expuestas en precedencia si aquellos "ya no son considerados exclusivamente como derechos públicos subjetivos de libertad que protegen una esfera individual determinada, sino que además pasan a adquirir una dimensión objetiva valorativa que informa todo el ordenamiento jurídico, es claro que sus alcances son mucho mayores que cualquier otra norma del ordenamiento como parámetro de constitucionalidad. Ello se hace más extensivo aún al derivar de ese carácter valórico una eficacia horizontal de estos mismos derechos, generando el denominado "efecto irradiación" de estos sobre todas las normas que conforman el ordenamiento. Así, los derechos fundamentales ya no se quedan en la norma constitucional misma y garantizando una posición jurídica concreta, sino además percolan todo el sistema jurídico, principalmente a través de los entresijos axiológicos que proclaman las propias normas. Esto da pie a que algún sector de la doctrina caracterice al Estado constitucional actual como una cultura o sociedad de los derechos fundamentales, destacando la función legitimadora del orden jurídico que ostentan estos" ${ }^{17}$.

\section{VALORES Y PRINCIPIOS JURÍDICOS EN LA JURISPRUDENCIA DE NUESTRO TRIBUNAL CONSTITUCIONAL}

Las ideas expuestas han sido en cierto modo recepcionadas en algunas sentencias de nuestro Tribunal Constitucional, aunque habitualmente son expresadas sin la claridad y elocuencia con la cual sus postuladores doctrinarios suelen enunciarlas. Asimismo, y más allá de las referencias explícitas o implícitas a un "valor" o "principio" de rango constitucional, en diversas ocasiones dicho tribunal pareciera argumentar en sus fallos no sobre la base de reconocer la procedencia de un método hermenéutico axiológico, sino que más bien a través de un procedimiento de interpretación teleológico o finalista bajo el cual, no obstante, entiende que subyace un determinado "valor" o "principio"18.

que la recogida en el texto a interpretar, no nos encontramos ante un exégeta auténtico, no es él un intérprete autorizado, carece de autoridad para hacerlo válidamente". BUSTOS (1986) p. 167. El TC alemán ha declarado que la Ley Fundamental establece un "orden objetivo de valores”. Según Zippeluis, las pautas de valoración que surgen de dicho orden deben ser seguidas por el juez "siempre que sean cognoscibles con suficiente claridad y posibiliten una resolución”. LARENZ (2001) pp. 144 y 146.

17 FERRADA (2004) pp. 128 y 129. Para una aproximación al tema de la "eficacia horizontal" de los derechos fundamentales en nuestro ordenamiento, puede verse FERNÁNDEZ (2002) y (2005). Para una crítica a esta doctrina, puede verse AldunATE (2003).

${ }^{18}$ A propósito de esta última afirmación, y refiriéndose a las necesarias zonas de discrecionalidad que enfrenta el interprete constitucional, Cea se expresa en los siguientes términos: "Empero, estas últimas no son en sí peligrosas cuando opera el criterio decisivo para fiscalizarlas, representado por un sistema de valores definido y articulado, como ethos o espíritu y telos o finalidad, en los principios y normas de la Carta Fundamental en el Estado democrático de Derecho. El postulado matriz que viene de ser aquí propugnado es el que, por lo demás, define la médula del constitucionalismo. Recuérdese que el sentido de aquel proceso civilizante es el del Poder racionalmente constreñido por el Derecho para servir a la persona. He aquí la fuente a la cual siempre debe retornarse para encontrar lo que Vaclav Havel, con hermosa metáfora, llama "la sal de un nuevo impulso en forma de una determinada espiritualización". Prólogo a ZAPATA (1994) p. IV. 
De otro lado, y muy lejos de pronunciarse en el marco de una dogmática general en este ámbito -por lo demás bastante escasa en nuestra literatura jurídica- los fallos que pueden citarse en tal sentido se han pronunciado con ocasión de un derecho fundamental específico o particular ${ }^{19}$.

Conforme a la sentencia pronunciada en causa rol $\mathrm{N}^{\circ} 46-1987$ “... se infiere con nitidez que el ordenamiento institucional estructurado por la Constitución de 1980 descansa sobre ciertos principios y valores básicos, entre los cuales, cabe señalar ...: la libertad del hombre, que los derechos fundamentales de la persona humana son anteriores y superiores al Estado y a la Constitución, razón por la cual esta no los crea sino que los "reconoce y asegura"; que el Estado en cumplimiento de su finalidad propia, cual es promover el bien común, debe darles segura y eficaz protección ...; que el ejercicio de la soberanía que se realiza por el pueblo y por las autoridades que la Constitución establece reconoce como limitación el respeto a los derechos esenciales que emanan de la naturaleza humana y, en fin, que nadie puede ser condenado por hechos anteriores a la norma jurídica que establece la pena" (Considerando 19०); "que todos estos principios se encarnan en disposiciones concretas de la Carta Fundamental como lo son, entre otros, los artículos $1^{\circ}, 4^{\circ}, 5^{\circ}$, inciso segundo, y 19, en especial su número 3, inciso séptimo" (Considerando $20^{\circ}$ ). Más adelante, el mismo fallo agrega que debe existir un consenso mínimo "en torno a ciertos principios y valores, algunos consustanciales a la naturaleza humana que el Estado tiene el deber de proclamar y defender y que están precisamente consignados en el Capitulo I relativo a las bases de la institucionalidad" (Considerando 46.).

En el fallo dictado en causa rol $\mathrm{N}^{\circ} 325-2001$, el tribunal también recurre a una argumentación de tipo axiológica al decidir en los siguientes términos: "Que, a propósito de lo sostenido en el considerando anterior, es importante y muy oportuno tener presente en la debida resolución del problema en examen, una regla de interpretación constitucional compartida por la unanimidad de la doctrina y de las magistraturas constitucionales del mundo actual. La resume con magistral claridad el profesor Segundo Linares Quintana en su Tratado de la Ciencia del Derecho Constitucional en los siguientes términos: "En la interpretación constitucional debe siempre prevalecer el contenido teleológico de la Constitución, que si es instrumento de gobierno, también y principalmente es restricción de poderes en amparo de la libertad individual. La finalidad suprema y última de la norma constitucional es la protección y la garantía de la libertad y la dignidad del hombre. Por consecuencia, la interpretación de la ley fundamental debe orientarse siempre hacia aquella meta suprema. $Y$ en caso de aparente conflicto entre la libertad y el interés del gobierno, aquella debe primar siempre sobre este último, porque no se concibe que la acción estatal manifestada a través de los cauces constitucionales pueda resultar incompatible con la libertad, que es el fin último del Estado ...” (Considerando 60 $)$.

19 Adicionalmente, se advierte una cierta promiscuidad conceptual en el uso de estas nociones por parte del Tribunal Constitucional, en cuanto pareciera emplear indistintamente los términos "valor", "principio", e incluso en ocasiones "norma", como si se tratare de conceptos sinónimos. 
En la sentencia recaída en causa rol No 146-1992, el Tribunal se expresa conforme a lo que sigue: "Que, el derecho consagrado en el artículo 19, $N^{\circ} 21$, antes transcrito, y que protege la libre iniciativa privada es una expresión de los contenidos filosófico-jurídicos del Capitulo I de la Constitución Política, y viene a ser una consecuencia del principio de subsidiariedad, como también del deber del Estado de resguardar el derecho de las personas a participar con igualdad de oportunidades en la vida nacional" (Considerando $8^{\circ}$ ). A propósito de lo mismo, en causa rol 167-1993 se señala que “... las normas del Capitulo I de nuestra Constitución constituyen un marco de carácter valórico y conceptual que vienen a limitar la acción del Estado dentro de la Sociedad, abriendo el mayor campo posible a la iniciativa de los particulares" (Considerando $10^{\circ}$ ).

Entre los fallos más recientes pueden citarse los siguientes:

(i) Roles No s. 608-609-610-611-612/2006: "La Carta Fundamental establece órganos legislativos, administrativos y jurisdiccionales, y cuando estos últimos controlan la constitucionalidad de los actos de los primeros, no pueden invadir su campo propio, por lo tanto, les está vedado entrar a calificar el mérito, oportunidad o conveniencia de la norma impugnada, debiendo limitar su pronunciamiento a la conformidad o disconformidad del acto de cuyo control se trate, con los principios, valores y normas constitucionales". (Considerando $13^{\circ}$ ).

(ii) Rol No 634-2006: "La doctrina italiana, entretanto, distingue entre intereses legitimos e intereses supraindividuales, siendo los primeros de carácter individual y los segundos de naturaleza colectiva o plural. Un interés legitimo es un interés posible de concretar y relevante para el derecho en la medida que la motivación que lo explica resulta acorde con los valores y los principios de la Constitución”. (Considerando $19^{\circ}$ ).

(iii) Rol No 591-2006: “... comprender la Constitución, como explica Willhelm Dilthey en su Teoría Hermenéutica, desentramando el significado de ella, sus conexiones de sentido, sobre la base de los valores que propugna, con cuya realización se compromete el Poder Constituyente y que prefiguran el Proyecto Máximo, el supremo objetivo de la comunidad nacional. Buscar esos valores, descubrirlos en los principios y normas en que aparecen articulados, para después comprenderlos y tratar de ponerlos en práctica, esa es la cláusula que propugnamos. Dignidad y derechos inalienables del hombre, ... son valores que, una vez localizados en las disposiciones constitucionales, posibilitan después determinar el correcto sentido y alcance de ellas, o sea, efectuar su legitima hermenéutica". (Considerando $9^{\circ}$ ).

(iv) Rol No 986-2007: "Que las disposiciones contenidas en los artículos 1 y 4 de la Ley Fundamental se reconocen, a la vez, como normas juridicas y como valores fundamentales del ordenamiento, que deben informar y guiar el actuar de todos los órganos del Estado. En tanto valores fundamentales, abstractos y generales, se concretan en otras normas especificas, tanto constitucionales como legales, las cuales, en tanto normas juridicas, deben ir acompañadas de medidas y remedios procesales que las garanticen. Dentro de dichas normas especificas se encuentran los derechos fundamentales invocados por la requirente, los cuales, al no verse infringidos, no puede considerarse que se encuentre lesionado (sic) su contexto valórico general, dentro del cual se incluyen los artículos 1 y 4 de la Constitución". (Considerando $37^{\circ}$ ). 
(v) Rol No 739-2007: "Por el contrario, interpretar el precepto guiándose por la presunción de legitimidad que emana de los actos del legislador, concordándola con los principios y valores constitucionales, parece razonable y coherente con la protección del orden público y el recto ejercicio del derecho de asociación que la Constitución consagra". (Considerando $17^{\circ}$ ).

(vi) Rol N 740-2008: “[Al Tribunal Constitucional] ... se ha encomendado la interpretación definitiva e inapelable de la Constitución, interpretación que debe desarrollarse en forma integral, esto es, considerando tanto la letra como los valores, principios y espiritu de la Carta Fundamental". (Considerando 20). "Los derechos, en cuanto valores sustantivos y autónomos, emanados de la dignidad del ser humano, deben ser diferenciados claramente de las denominadas garantías, que en tanto instituciones juridicas de carácter adjetivo, técnicas o herramientas, procuran el aseguramiento de los derechos". (Voto disidente ministro Vodanovic) ${ }^{20}$

\section{RIESGOS O PELIGROS QUE ACARREA EL USO INDISCRIMINADO DE LOS VALORES Y PRINCIPIOS JURÍDICOS COMO ELEMENTOS DE LA INTERPRETACIÓN CONSTITUCIONAL}

Ahora bien, como resulta fácil comprender, la concepción que se tenga acerca de la naturaleza y función de los derechos fundamentales, e incluso antes que eso, la teoría que se siga acerca de la propia Constitución, son cuestiones determinantes a los efectos de interpretar el contenido y alcance de las disposiciones incorporadas al texto políti$\mathrm{Co}^{21}$. Para el tema que se aborda en estas notas, interesa destacar que un primer problema que presenta la opinión que concibe los derechos fundamentales como "principios" o "valores" - o bien que se aproxime a una interpretación axiológica para determinar su contenido o extensión- tiene que ver -como apunta Böckenförde- con el hecho de que

${ }^{20}$ En lo tocante a la invocación de "principios", también hallamos pronunciamientos del Tribunal Constitucional expresamente referidos a derechos fundamentales. Así, por ejemplo, a propósito de la aplicación de las garantías de que gozan los individuos en el ámbito penal y su aplicación al campo del derecho administrativo sancionador, en la causa rol $\mathrm{N}^{\circ} 244-1996$, se falló que "los principios inspiradores del orden penal contemplados en la Constitución Política de la República han de aplicarse, por regla general, al derecho administrativo sancionador, puesto que ambos son manifestaciones del ius puniendi propio del Estado". (Considerando $9^{\circ}$ ). En el mismo sentido, la sentencia recaída en la causa rol $N^{\circ} 480-2006$, profundizando sobre este mismo particular manifestó que "... aunque se adopte entonces la doctrina que asimila ambos sistemas, se hace necesario luego reconocer las diferencias y construir una linea jurisprudencial y doctrinaria propia del Derecho Administrativo, en conformidad a los principios de esta rama y teniendo especialmente presente las garantías patrimoniales y de la libertad económica y no las de la libertad personal, cuando son las primeras y no las segundas las que están en juego". (Considerando $10^{\circ}$ ).

${ }^{21}$ Una exposición sinóptica sobre este particular, a partir de la obra de Böckenförde, puede verse en Aldunate (2008) p. 97. De otro lado, se advierte que el configurar la Constitución "como un sistema de valores plantea el problema de que una deducción de esos valores para solucionar el caso concreto olvidaría que la norma fundamental aparece, en expresión de Haeberle, como una "apertura" (Offentlichkeitbezug) que el Derecho Natural (que, a fin de cuentas, es lo que significa un sistema institucionalizado y objetivamente válido de valores) no puede tematizar. La Ley Fundamental, dice el autor, aparece así como un offentliche Prozess en el cual una aplicación estricta a partir de un sistema de valores fijos impediría el "proceso de crecimiento" del propio sistema constitucional". CARRASCO (1984) p. 42. 
una tal concepción se enfrenta a la inexistencia de un método que permita fundar racionalmente un orden de valores o una jerarquía entre ellos ${ }^{22}$.

En lo que toca a la interpretación constitucional $-\mathrm{y}$ especialmente cuando de derechos fundamentales se trate- la legitimidad de las decisiones del Tribunal Constitucional está dada por la calidad de su argumentación, en cuanto este pueda fundamentar su decisión en el texto constitucional a través de un razonamiento propiamente jurídi$\mathrm{Co}^{23}$. Dicha exigencia es particularmente relevante en materia constitucional si, como dice Aldunate, se considera que "el estrés interpretativo al que se ve sometida la Constitución es mucho más intenso que aquel a que se ven sometidos otros cuerpos normativos, tanto por su estructura como por los efectos que se derivan de su aplicación" ${ }^{24}$.

Es precisamente en el contexto que se reseña donde se cristalizan o aprecian los mayores riesgos o peligros que entraña una interpretación constitucional basada, de un modo exclusivo, en la noción de un "valor" o "principio" que se entiende subyacente en la configuración de un derecho fundamental, cualquiera fuere este. En efecto, la argumentación que se estructure únicamente sobre una tal premisa, dando por supuesto aquello que no aparece en el texto o que pueda desprenderse de él sobre la base de un razonamiento objetivo, implica dejar librado al intérprete un margen de subjetividad que le habilita para traducir, como norma, solo aquello que se conforme con su propia y personal opinión. Así las cosas, la invocación o llamamiento de un "valor" o "principio" que simplemente se estime ínsito en un cierto precepto, a más de prescindir del rol de acotamiento de la actividad interpretativa que cumplen los textos, podría implicar una suerte de "patente de corso", ora para elevar a la categoría de derecho fundamental determinadas aspiraciones del mismo intérprete, ora para ponderar y jerarquizar dere-

\footnotetext{
22 ALdunate (2008) p. 97. Entre nosotros, algunos han pretendido hallar pautas que permitirían establecer tales jerarquías, PFEFFER (1998). Refiriéndose a un fallo del Tribunal Constitucional español, Aguiar de Luque señala que "cuando para resolver ese problema se recurre a la llamada ponderación de bienes es obvio que la respuesta no tendrá ya su fundamento en la exégesis del derecho constitucional positivo propiamente dicho, sino en una valoración en la que cabe tener en cuenta circunstancias tan ajenas a lo constitucional como las que se han citado en la sentencia 121/1982". AgUiAR De LUQUE (1993) p. 23.

${ }^{23}$ AldDUNATE (1995) p. 27. Según Salazar, "la exigencia de que la decisión sea fundada significa que el TC debe analizar los argumentos a favor y en contra de la constitucionalidad de la interpretación acogida, como también a favor y en contra de las otras interpretaciones que se presentaron como alternativas". Lo anterior, asimismo, "permite que los mismos argumentos puedan ser aplicados en casos similares. Así, el peso de las decisiones del TC va más allá del caso concreto que resuelven. Ello contribuye a evitar contradicciones en la jurisprudencia constitucional. Aunque el TC no está obligado a resolver de acuerdo a lo decidido en un caso anterior, la garantía constitucional de la igualdad ante la ley se refuerza si el máximo órgano de la justicia constitucional aplica el mismo razonamiento en casos similares, lo que equivale a aplicar las normas jurídicas en el mismo sentido, a darles la misma interpretación. Tal circunstancia constituye un factor importante de la seguridad jurídica”. SALAZAR (1993) p. 467.

24 AldunAte (1998) p. 28. De ahí que el mismo autor exprese: "De lo que se trata, entonces, es de encontrar un método capaz de disciplinar el proceso desarrollado por el juez a la vista de lo que realmente sucede. $\mathrm{Y}$ esto es un fenómeno de asignación de significado a las señales de lenguaje contenidas en un texto. Por lo tanto, la formulación de reglas de interpretación no irá por el punto de encontrar el sentido previamente existente en el texto, sino de reglas que permitan justificar o acotar el margen dentro del cual el juez asigna un significado a un texto normativo, y toma sobre esa base ("sujeción al derecho") una decisión vinculante". (p. 31)
} 
chos o libertades a su propio amaño y para las cuales la Constitución no ha contemplado reglas. Lo dicho se agrava, aún más, si se tiene presente tanto el origen del Tribunal Constitucional -diverso de la representación democrática que ostentan otros órganos constitucionales- como la circunstancia - por lo demás natural si se quiere asegurar la "supremacía" de la Constitución- de no responder ante una autoridad jerárquicamente superior.

Quienes propugnan una interpretación de la Constitución en general, o de los derechos fundamentales, en lo más específico, sobre la base de "principios" o "valores", tal vez procurarán refutar a sus críticos fundándose en las observaciones de Esser en cuanto apunta que "el razonamiento jurídico no se realiza oficialmente en el plano de los principios, y se diría que los principios no son ni patrón ni objeto de la resolución judicial, quoad auctoritatem iuris. Pero aunque el juez "prudente" procura y sabe evitar las exposiciones y formulaciones de principios, no es menos cierto que para él y para sus críticos los principios están siempre en el fondo del caso. Ellos son los que determinan el tratamiento dado al caso particular, aunque en lugar de "principles" se citen "precedents". Y aunque solo la masa de estos constituya oficialmente el Derecho, ocurre lo mismo que con la masa textual de nuestros códigos: "aplicables" lo son solo los textos, pero lo que decide su aplicación en derecho son los principios que existen antes y más allá de los textos; solo que el fanático del texto oculta tal estado de cosas con su intento de encontrar también los principios en el texto, "sin mirar más allá de las cuatro esquinas del Código" 25 .

Una observación como la expuesta y que, atendida su aparente correspondencia con la praxis judicial, a primera vista tendría la virtud de seducir, podría, no obstante, ser explicada mediante la distinción que algunos formulan entre el "contexto de descubrimiento" y el "contexto de justificación" de una teoría cualquiera. La primera expresión, para aludir al proceso en el que se descubre o formula una teoría; y, la segunda, en referencia al proceso o actividad de validarla o justificarla. A diferencia del "contexto de descubrimiento", en este último aspecto sí habría una "lógica de la justificación" que vendría dada por lo que se conoce como el método científico y que es independiente de lo primero. "Esta distinción ha sido utilizada en el ámbito de la teoría de la argumentación jurídica. En particular, en el caso de las decisiones judiciales, la transposición se ha hecho para distinguir entre lo que puedan ser los móviles psicológicos, el contexto social, las circunstancias ideológicas que puedan haber llevado a un juez a dictar una determinada resolución, por un lado; y, por otro, las razones que el juez alega para tratar de mostrar que su decisión es correcta o válida. Mientras que respecto de lo primero

25 ESSER (1961) p. 251. Por lo demás, la constatación de la que pretende dar cuenta Esser, en modo alguno implica dejar el tema librado a la arbitrariedad del juez o eximir del requisito de que las decisiones deban ser razonadas. En este sentido y "como ha sido puesto en evidencia por Gadamer, la presencia de una precomprensión es, por lo demás, algo completamente normal, general en los procesos hermenéuticos (no es cosa que sea propia únicamente de la interpretación jurídica). Así, las operaciones intelectuales para la aplicación del derecho constituyen medios para "extraer" del sistema jurídico-positivo determinadas prevaloraciones (Vorbewertungen), unas valoraciones previas cuyo contenido es de política jurídica". HABA (1999) p. 57. 
cabrían estudios de tipo empírico, lo segundo vendría gobernado por lo que se llama el método jurídico. Del mismo modo, aquí se produciría también una independencia entre unas cuestiones y otras: la corrección de una decisión judicial vendría dada por la corrección de las razones dadas por el juez en su resolución y sería, en este sentido, lógicamente independiente del contexto de descubrimiento en que se ha producido". En definitiva, sucede que "los jueces tienen el deber de justificar sus decisiones -mostrarlas como correctas- pero no el de explicarlas". Y es por ello que "el deber de independencia de los jueces tiene su correlato en el derecho de los ciudadanos a ser juzgados desde el Derecho, no desde relaciones de poder, juegos de intereses o sistemas de valores extraños al Derecho (...) El principio de independencia protege no solo la aplicación del Derecho, esto es, el fallo y las razones que se aducen en favor del fallo, sino que además exige al juez que falle por las razones que el Derecho le suministra" ${ }^{26}$. Se sigue de lo dicho, la importancia de la argumentación en las pertinentes decisiones judiciales cuya finalidad, al decir de Perelman, es precisamente "fortalecer la adhesión del auditorio", en cuanto es tal adhesión la que, en definitiva, otorga racionalidad al argumento en cuestión ${ }^{27}$.

Para terminar, consignemos que los peligros ya anotados que encierra aproximarse axiológicamente a la interpretación de los derechos fundamentales cobran especial relieve si se entiende, como ocurre con la generalidad de nuestros autores, que los preceptos constitucionales -en virtud de lo prevenido en los artículos $6^{\circ}$ y $7^{\circ}$ de la Carta Políticadeben ser aplicados directamente por el juez -cualquiera que este sea- sin requerir de una suerte de función "mediadora” que en algún momento se le asignó a la ley ${ }^{28}$. De este modo, concibiéndose la Constitución como una fuente del Derecho - "fuente de las fuentes" la llama Rubio Llorente ${ }^{29}$ - y de aceptarse, también, un método de interpretación meramente valorativo a partir del cual se determine la configuración de los derechos fundamentales (expuestos también hoy día a un fenómeno de "inflación” merced del influjo del derecho internacional y la praxis que exhibe nuestro recurso de protección), existe el riesgo cierto de abrir un cauce para un sistema de creación judicial del derecho

\footnotetext{
${ }^{26}$ AgUiLó (1997) pp. 71-73 y 76-77. En términos generales, "en materia decisoria judicial entendemos por justificar o fundamentar a la exposición de los argumentos o las razones suficientes y apropiadas para establecer la validez jurídica de las decisiones judiciales". VIGO (1998) p. 495.

${ }^{27}$ Citado por BAZAN Y MADRID (1991) p. 186. En igual predicamento, Dworkin apunta "la comunidad jurídica debe evaluar a los jueces con criterios intelectuales. Insistiremos en que elaboren los mejores argumentos que les sea posible, y luego nos preguntaremos si sus argumentos son lo suficientemente buenos. Por supuesto, no hay fórmula que garantice que los jueces no serán influidos por los malos argumentos (...). Todo lo que podemos hacer ante esas malas decisiones es señalar cómo y dónde los argumentos eran malos o las convicciones inaceptables". Citado por IgLESIAS (2000) p. 102. Similar opinión puede verse en VIEHWEG, p. 194; en CALSAMIGLIA, p. 129; y en BARRAGÁN (1990) p. 72.

${ }^{28}$ Nuestro Tribunal Constitucional se ha manifestado explícitamente a favor de esta tesis. Así, por ejemplo, en su sentencia en causa rol $N^{\circ} 46-1987$, expresa que "... que todos estos principios se encarnan en disposiciones concretas de la Carta Fundamental como lo son, entre otros, los artículos $1^{\circ}, 4^{\circ}, 5^{\circ}$, inciso segundo, y 19, en especial su número 3, inciso séptimo" (Considerando $20^{\circ}$ ); y "que estos preceptos no son meramente declarativos sino que constituyen disposiciones expresas que obligan a gobernantes y gobernados tanto en si mismas, como también, en cuanto normas rectoras y vitales que coadyuvan a desentrañar el verdadero sentido y espiritu del resto de las disposiciones de la Constitución". (Considerando $21^{\circ}$ )

${ }^{29}$ Rubio (1979) p. 62.
} 
que, en la práctica, no difiera mucho de las doctrinas que en su momento formuló Ehrlich $^{30}$. Con todo, una tal objeción -entiéndase bien- no implica oponerse al rol "creador" que bajo ciertos respectos compete a los jueces, sino que simplemente importa resaltar que dicha labor debe situarse en un contexto jurídico en el cual se halla limitada la subjetividad del intérprete y en que el "texto", quizás con mucha mayor intensidad que en otros ámbitos del derecho, cumple la función de acotarla.

En definitiva, aquellos que critican, entre otras concepciones, una interpretación axiológica de las normas referidas a derechos fundamentales, advierten que partiendo de una ausencia de teorización y comprensión adecuada de la doctrina alemana "y su trasposición imperfecta al derecho chileno -llegando a entender la doctrina de la Drittwirkung como una habilitación general para la aplicación directa e inmediata de los derechos fundamentales entre particulares y no como deber del Estado de criterio interpretativo para resolver los conflictos entre estos"-, asistimos a un "fenómeno de reducción del derecho chileno a un catálogo de derechos fundamentales de contenido vagoroso e impreciso, sobredimensionado en su operatividad y reducido en sus soluciones jurídicas a una comprensión más o menos arbitraria de su contenido, generándose un proceso de "desconstitucionalización” y "vulgarización” del derecho", como la llama Aldunate $^{31}$. El mismo Aldunate lo expresa con extrema claridad en los siguientes términos: "La vigencia de 20 años de la Constitución de 1980 se encuentra asociada, desde sus inicios, a una fuerte afirmación de su carácter de norma jurídica directamente vinculante para los órganos públicos, como norma justiciable. En sí, esto no merece crítica alguna, y puede valorarse positivamente. Sin embargo, si se enfatiza el carácter de la Constitución como norma directamente aplicable, pero por otro lado se descuida toda la estructura y fundamento de la comprensión de la Constitución como instrumento de gobierno al servicio del equilibrio entre autoridad y libertad, constitutivo del orden político, existe la posibilidad de transformarla, simplemente, en una norma más (...) la recepción de la Constitución como precepto directamente aplicable no ha ido acompañada de la correspondiente y necesaria elaboración doctrinaria que permita aplicarla, en tanto Constitución, como norma distinta a otras (...) La jurisprudencia, apoyada por ciertos sectores de la doctrina, ha ido expandiendo cada vez más el sentido de los derechos constitucionales, al punto que su catálogo no constituye ya el núcleo fundamental e inviolable de la dignidad humana, una especie de reserva intangible, sino que se ha transformado en un espacio abierto, una suerte de sitio eriazo en el cual es posible encontrar casi cualquier cosa, desde la protección a animales hasta al defensa del prestigio profesional y el trazado específico de un recorrido de taxis colectivos" 32 .

\footnotetext{
30 Peligros como el anotado han llevado a que algunos, como Forsthoff, incluso postulen un regreso "a las reglas tradicionales de la hermenéutica jurídica, tal como fueron expuestas sobre todo por Savigny". Citado por LARENZ (2001) p. 161.

${ }^{31}$ FERRADA (2004) p. 130.

32 Aldunate (2001) pp. 28, 29 y 32. El hecho de entender la Constitución "como una norma más" tiene también consecuencias en el plano de las reglas hermenéuticas que le son aplicables. En este sentido puede verse SALAZAR (1993), pág. 471 y, para el caso español, Aguiar de Luque, quien expresa que "el aspecto más problemático es ... el de la aplicación a los derechos fundamentales de los límites al ejercicio de los
} 


\section{CONCLUSIONES}

Para terminar, y teniendo presente lo expuesto a través de estas notas, cabe consignar, a modo de conclusión, las siguientes consideraciones:

1.- Independiente de la mayor o menor bondad que pueda predicarse respecto del entendimiento de la Constitución como una suerte de "programa" antes que concebirla como cauce de un proceso político, quienes adhieren a la primera posición pareciera que, en una mucha mayor medida que los seguidores de esta última corriente, suelen invocar la existencia de "valores" o "principios"-cualquiera que sea la conceptualización que se tenga de los mismos- como elemento esencial a considerar a la hora de interpretar su texto. Dicha orientación coincide, a su vez, con una aproximación más bien axiológica a la hermenéutica constitucional y que, por lo mismo, manifiesta una abierta preferencia por los métodos "valorativos", "teleológicos" y "finalistas" de interpretación constitucional.

2.- Un sector importante de la doctrina nacional, así como diversos fallos de nuestro Tribunal Constitucional, suelen recurrir a la noción de "principio" o "valor" a fin de justificar sus pertinentes opiniones o decisiones jurisdiccionales; echándose en falta, en diversas ocasiones, el desarrollo de una mayor argumentación jurídica que justifique, en términos objetivos y de manera suficiente, una determinada posición. Ello es particularmente notorio a propósito de materias tales como la forma de entender configurado el "ámbito protegido" de ciertos derechos fundamentales o el criterio seguido para ponderarlos en determinadas circunstancias.

3.- Sin desconocer el hecho de que los valores y principios pueden -y debenefectivamente incidir en la labor interpretativa, la circunstancia de basarse exclusivamente en tales categorías para determinar el sentido y alcance de los preceptos constitucionales encierra, a nuestro juicio, riesgos o peligros evidentes. En concreto, y especialmente vinculado al tema de estas notas, semejante proceder puede importar dejar librado al intérprete un margen de subjetividad excesivamente amplio que, a la postre, signifique consagrar como "válida" únicamente aquella interpretación que se adecua a su propia y personal opinión. De este modo, la simple aseveración -no justificada jurídicamente y en el pertinente texto- acerca de estimar subyacente un determinado "valor" o "principio" en un cierto precepto constitucional, a más de prescindir del rol de acotamiento de la actividad interpretativa que cumplen los textos, podría permitir extremos tales como elevar a la categoría de derecho fundamental determinadas aspiraciones del mismo intérprete, o bien la posibilidad de ponderar y jerarquizar derechos o libertades en un ámbito donde la Constitución no ha contemplado reglas ni definido criterios. Si a

derechos que consagra el Título Preliminar del Código Civil, y en concreto la aplicabilidad de las nociones de ejercicio de buena fe y abuso del derecho. La posibilidad de extrapolación de tales nociones es algo que se ha plasmado en varias resoluciones y sentencias del Tribunal Constitucional, hasta el punto de que hoy puede afirmarse que constituye una constante interpretativa de nuestra jurisprudencia constitucional”. AgUiAR DE LUQUE (1993) p. 32. 
lo anterior se suma la opinión prácticamente generalizada en nuestro país acerca de la denominada "eficacia horizontal inmediata" de los derechos fundamentales, se comprenderá, entonces, que la prevención señalada se torna todavía más apremiante.

4.- Los riesgos o peligros que se han destacado en precedencia, a nuestro parecer se agudizan si se tiene además presente, por un lado, el origen del Tribunal Constitucional -diverso de la representación democrática que ostentan otros órganos constitucionales- y, por el otro, el hecho de que en función de la salvaguarda de la supremacía constitucional, dicha magistratura no cuente con una autoridad jerárquicamente superior que revise sus decisiones. De ahí también la necesidad que se plantea en orden a que la comunidad en general, aunque de un modo particular los juristas, ejerzan una función crítica respecto de las resoluciones de la judicatura constitucional, lo que a su turno exigirá de esta que sus decisiones aparezcan jurídicamente suficientes y, al mismo tiempo, se presenten debidamente justificadas.

\section{BIBLIOGRAFÍA CITADA}

Aguiar De LuQue, Luis (1993): "Los límites de los derechos fundamentales" Revista del Centro de Estudios Constitucionales $\mathrm{N}^{\circ}$ 14: pp. 9-34.

Aguiló, Josep (1997): "Independencia e imparcialidad de los jueces y argumentación jurídica” Isonomía, N 6: pp. 71-79

Alexy, Robert (1998): "Sistema jurídico, Principios Jurídicos y Razón Práctica”, Doxa $\mathrm{N}^{\circ}$ 5: pp. 139-151.

AlEXY, Robert (2003): Teoría de los derechos fundamentales (Madrid, Centro de Estudios Políticos y Constitucionales) 608 pp.

AldunAte Lizana, Eduardo (1995): "Deficiencias en la argumentación jurídica. Comentario crítico al fallo del Tribunal Constitucional librado en la causa Rol No 207”, Revista de Derecho, Universidad Católica de Valparaíso, vol. XVI: pp. 27-44.

Aldunate Lizana, Eduardo (1998): “Consideraciones Preliminares para una Teoría de la Interpretación Jurídica", Revista Chilena de Derecho, Número Especial: pp. 27-31.

AldunATE LizanA, Eduardo (2001): "La desconstitucionalización de la Constitución", Revista de Derecho, Universidad Católica de Valparaíso, vol. XXII: pp. 17-38.

AldunATE LiZANA, Eduardo (2003): "El efecto irradiación de los derechos fundamentales”, VV.AA, La Constitucionalización del Derecho Chileno, Universidad Austral de Chile y Editorial Jurídica de Chile: pp. 13-38.

Aldunate LizAna, Eduardo (2008): Derechos Fundamentales (libro actualmente en prensa). Altamira Gigena, Julio Isidro (1972): Los Principios Generales del Derecho como Fuente del Derecho Administrativo (Buenos Aires, Astrea de Rodolfo Depalma y Hnos.) 82 pp.

ArCe y Flórez VAldés, Joaquín (1990): Los Principios Generales del Derecho y su formulación constitucional (Madrid, Civitas) 163 pp.

BARRAGÁN, Julia (1990): "La respuesta correcta única y la justificación de la decisión jurídica”, Doxa No 8: pp. 63-72. 
BARros, Enrique (1981): "La interpretación de la Constitución desde la perspectiva de la Teoría del Derecho", Revista de Derecho Público No 29-30: pp. 25-33.

BARros, Enrique (1984): "Reglas y Principios en el Derecho", Anuario de Filosofía Jurídica y Social, Sociedad Chilena de Filosofía Jurídica y Social, Valparaíso Edeval: pp. 269-281.

BAZÁN, José Luis y MADRID, Raúl (1991): "Racionalidad y Razonabilidad en el Derecho", Revista Chilena de Derecho, vol. 18, N²: pp. 179-188.

Bustos Concha, Ismael (1986): "La hermenéutica constitucional”, Revista de Derecho Universidad Católica de Valparaíso, Vol. X: pp. 157-168;

Carrasco D., Manuel (1997): "La Interpretación de la Constitución”, Revista de Derecho Universidad Católica del Norte, Sede Coquimbo: pp. 113-131.

Calsamiglia, Albert (1988): Introducción a la Ciencia del Derecho (Madrid, Ariel) $155 \mathrm{pp}$.

CArrasco Perera, A. (1984): "El juicio de razonabilidad en la justicia constitucional", Revista Española de Derecho Constitucional, $\mathrm{N}^{\circ} 11$ : pp. 36-106.

Carretero Pérez, Adolfo (1979): "El Concepto Constitucional de Fuentes del Derecho", en: VV.AA, La Constitución Española y las Fuentes del Derecho, vol. I, Madrid, Instituto de Estudios Fiscales: pp. 385-419.

Castedo Álvarez, Fernando (1979): "La Constitución como Fuente de Derechos", VVAA, La Constitución Española y las Fuentes del Derecho, vol. I, Madrid, Instituto de Estudios Fiscales: pp. 423-455.

CEA, José Luis (1984): "Hermenéutica Constitucional, Soberanía Legal y Discrecionalidad Administrativa", Revista Chilena de Derecho, Pontificia Universidad Católica de Chile, vol. XI, $\mathrm{N}^{\circ} 1$ : pp.7-16.

CEA, José Luis (1992): “La interpretación axiológica de la Constitución,” en: VV.AA. Interpretación, integración y razonamiento juridicos (Santiago, Edit. U. de Chile y U. Adolfo Ibáñez) pp.87-97.

Courcelle-Seneuil, Juan Gustavo (1986): "El Fundamento de los Principios del Derecho", Anuario de Filosofía Jurídica y Social, Sociedad Chilena de Filosofía Jurídica y Social: pp. 113-120.

Cumplido Cereceda, Francisco (1995): "Los valores de la Constitución de 1980 y su eficacia jurídica”, Revista de Derecho Público, Universidad de Chile, No 57-58: pp. 131-146.

Del Vecchio, Giorgio (1948): Los Principios Generales del Derecho (Barcelona, Bosch), 149 pp.

Díez-PICAZO, Luis y GULLÓN, Antonio (1989): Sistema de Derecho Civil (Madrid, Tecnos) vol. I, 630 pp.

DWORKIN, Ronald (1984): Los derechos en serio (Barcelona, Editorial Ariel) 508 pp.

ESSER, Josef (1961): Principio y Norma en la Elaboración Jurisprudencial del Derecho Privado (Barcelona, Bosch) 498 pp.

FernándeZ, Miguel Ángel (2002): "Fundamentos Constitucionales del Derecho de los Contratos: Intangibilidad, Autonomía de la Voluntad y Buena Fe", Cuadernos de Extensión Jurídica $\mathrm{N}^{\circ}$ 6, Santiago, Universidad de los Andes: pp. 17-46. 
FERnÁNDeZ, Miguel Ángel (2005): “Constitución y Autonomía de la Voluntad”, en: VVAA, Sesquicentenario del Código Civil de Andrés Bello, T. II (Santiago, Facultad de Derecho de la Universidad de Chile y LexisNexis) pp. 1245-1269.

FERrADA, Juan Carlos (2004): "Los derechos fundamentales y el control constitucional", Revista de Derecho, Universidad Austral, vol. XVII: pp. 113-137.

FINNIS, John (2000): Ley natural y derechos naturales (Buenos Aires, Abeledo Perrot) 456 pp.

FreiXes SANJUÁn, T. y REMOTTI CARBOnell, J.C. (1992): "Los valores y principios en la interpretación constitucional”, Revista Española de Derecho Constitucional $\mathrm{N}^{\circ} 35$ : pp. 97-109.

GARCÍA DE ENTERRÍA, Eduardo (1984): Reflexiones sobre la Ley y los principios generales del Derecho (Madrid, Civitas) 182 pp.

GonZÁlez P., Jesús (1983): El Principio General de la Buena Fe en el Derecho Administrativo (Madrid, Civitas) 160 pp.

Gordillo Cañas, Antonio (1990): Ley, Principios Generales y Constitución: Apuntes para una relectura, desde la Constitución, de la teoría de las Fuentes del Derecho (Madrid, Centro de Estudios Ramón Areces) 144 pp.

HABA, Enrique P. (1999): "Precomprensiones, racionalidad y métodos en la resoluciones judiciales," Doxa, No 22: pp. 49-78.

IgLESIAS VILA, Marisa (2000): "Los conceptos esencialmente controvertidos en la interpretación constitucional”, Doxa, No 23: pp. 77-104

LarenZ, Karl (2001): Metodología de la Ciencia del Derecho (Barcelona, Editorial Ariel) $536 \mathrm{pp}$.

Mans Puigarnau, (1947): Los Principios Generales del Derecho. Repertorio de Reglas, Máximas y Aforismos Jurídicos con la Jurisprudencia del Tribunal Supremo de Justicia, (Barcelona, Casa Editorial Bosch) 525 pp.

Moderne, Franck (2005): Principios Generales del Derecho Público (Compilación y traducción de Vergara Blanco, Alejandro, Editorial Jurídica de Chile, Santiago) $301 \mathrm{pp}$.

OELCKERS, Osvaldo (1992): “Jerarquía, Integración y Unidad del Sistema Jurídico Administrativo", en: VVAA, Interpretación, Integración y Razonamiento Jurídicos, Santiago, Universidad de Chile, Universidad A. Ibáñez y Editorial Jurídica de Chile, pp. 363-376.

Peczenik, A. (1992): "Los principios jurídicos según Manuel Atienza y Juan Ruiz Manero”, Doxa, N¹2: pp. 327-331.

PfEFfER, Emilio, (1998): "Algunos criterios que permiten solucionar el conflicto derivado de la colisión de derechos", Revista Chilena de Derecho, Número Especial: pp. 225-227.

PRIETO SANCHÍS, Luis“(1996): “Diez argumentos a propósito de los principios,” Jueces para la Democracia, No 26: pp. 41-49

Puig PeÑa, Federico (1956): "Los Principios Generales del Derecho como Fuente Normativa de la Decisión Judicial”, Revista de Derecho Privado, T. XL, Madrid: pp. 10471065 . 
QUINTANA BRAVO, Fernando (1994): Interpretación, Ratio Iuris y Objetividad (Valparaíso, Edeval) 245 pp.

RAMÓn LEAL, Alberto (1979): “Los Métodos de Interpretación Constitucional”, Revista de Derecho Público $N^{\circ}$ s 25-26: pp. 57-69.

REAL, Alberto Ramón (1976): "Los Principios Generales de Derecho en el Derecho Administrativo", Revista de Derecho Público, N¹9-20: pp. 231-262.

Ríos Álvarez, Lautaro (1985): "Dos Reflexiones acerca de los Principios Generales del Derecho”, Revista de Ciencias Sociales Nos 26/27:, Primer y Segundo Semestres, pp. 61-96.

Rubio Llorente, Francisco (1979): “La Constitución como Fuente del Derecho", VVAA, La Constitución Española y las Fuentes del Derecho, vol. I (Madrid, Instituto de Estudios Fiscales) pp. 51-73.

Ruiz-Tagle Vial, Pablo (2001): "Una dogmática general para los Derechos Fundamentales en Chile”, Revista de Derecho Público, No 63: pp. 179-199.

SALAZAR SÁNCHEZ, Marta (1993): "Interpretación de la Constitución y control de la ley interpretativa por el Tribunal Constitucional", Revista Chilena de Derecho, Vol. XX, $N^{\circ} 2-3$ : pp. 467-473.

SÁncheZ de la TORRe, Ángel (1975): Los Principios Clásicos del Derecho (Madrid, Unión Editorial) 241 pp.

SANCHO Rebullida, Francisco de Asís (1978): "Los principios generales del Derecho", VVAA, "Estudios de Derecho Civil" T. I, Pamplona, Ediciones Universidad de Navarra, pp. 41-58.

Silva BASCUÑán, Alejandro (1979): "La Constitución Jurídica”, Revista Chilena de Derecho, Vol. VI, $\mathrm{N}^{\circ}$ 1-4: pp. 111-133.

VAldeCASAs G., Guillermo, (1975): "Los Principios Generales del Derecho en el nuevo título preliminar del Código Civil", Anuario de Derecho Civil, vol. $\mathrm{N}^{\circ}$ 28, Madrid, Publicaciones del Instituto Nacional de Estudios Jurídicos, pp. 331-336.

VIEHWEg, Theodor (1991): Tópica y Filosofía del Derecho (Barcelona, Gedisa) 201 pp.

Vigo, Rodolfo (1986): "Los Principios Generales del Derecho", Revista de Jurisprudencia Argentina, Diario 20-8-86.

Vigo, Rodolfo (1998): "Razonamiento judicial justificatorio", Doxa, No 21: pp. 483499.

ZaPATA, Patricio (1994): La Jurisprudencia del Tribunal Constitucional (Santiago, Imprenta Vis Ltda.) $286 \mathrm{pp.}$

Zuñiga URbina, Francisco (1992): “Tendencias contemporáneas en la interpretación de la Constitución”, VVAA, Interpretación, integración y razonamiento jurídicos (Santiago, Edit. U. de Chile y U. Adolfo Ibáñez) pp. 285-303. 